\title{
Propuesta investigativa EN TORNO AL DESARrollo DEMOCRÁTICO DE LA SOCIEDAD CHILENA*
}

\author{
Kamel Cazor Aliste** \\ Ismael Bustos Concha** \\ Yanira Zúñiga Añazco ${ }^{* * * *}$
}

RESUMEN: La propuesta reflexiona en torno al desarrollo democrático de la sociedad chilena a la luz de la articulación entre democracia política y democracia constitucional; todo lo cual, a fin de poder avanzar en el conocimiento de su actual proceso de democratización que, no obstante ir encaminado a una democracia más plena, exteriorizaría un déficit en su sociedad política.

\section{Palabras clave: Democracia - Política - Constitución.}

ABSTRACT: The proposal reflects around the democratic development of the Chilean society to the light of the joint between political democracy and constitutional democracy; everything which, in order to be able to advance in the knowledge of its present process of democratization that, despite going directed to one more a more total democracy, would express a deficit in its political society.

\section{KeY wORDs: Democracy - Politics - Constitution.}

SUMARIO: I. Introducción. II. El problema. 2.1. Planteamiento del problema. 2.2. Formulación del problema. 2.3. Sistematización del problema. 2.4. Objetivos de la investigación. a. Objetivo general. B. Objetivos específicos. 2.5. Justificación de la investigación. III. El marco teórico. 3.1. Antecedentes de la investigación. 3.2. Bases teóricas de la investigación. 3.2.1. La democracia como expresión política: contenido y umbrales democráticos. 3.2.2. La

* Este trabajo forma parte del Proyecto Fondecyt N 1050378 (2005-2006) titulado "El desarrollo democrático de la sociedad chilena a la luz de la articulación entre democracia política y democracia constitucional", del que su primer autor es investigador principal y los demás autores coinvestigadores.

** Doctor en Derecho, Profesor de Derecho Constitucional, Universidad Católica del NorteCoquimbo.

*** Magíster en Derecho, Profesor de Filosofía del Derecho, Universidad Central de Chile.

**** Doctora en Derecho, Profesora de Derecho Internacional Público, Universidad Austral de Chile.

Artículo recibido el 6 de septiembre de 2005. Aprobado por el Comité Editorial el 14 de noviembre de 2005 . 
democracia como expresión jurídica: Estado constitucional y desarrollo democrático de la sociedad chilena. 3.3. Hipótesis. 3.4. Variables e indicadores. 3.4.1. Variable independiente. 1. Definición conceptual. 2. Definición operacional. 3.4.2. Variable dependiente. 1. Definición conceptual. 2. Definición operacional. IV. Marco metodológico. 4.1. Tipos y niveles de investigación. 4.2. Métodos de investigación.

\section{INTRODUCCIÓN}

En el presente trabajo se expondrá la propuesta investigativa que permitirá abordar el grado de desarrollo democrático de la sociedad chilena. A fin de poder avanzar en el conocimiento de su actual proceso de democratización que, no obstante ir encaminado a una democracia más plena, exterioriza un déficit en su sociedad política, que no solo abarca diversos comportamientos sociales (democracia política), sino que también comprende, en la perspectiva del Estado constitucional, el divorcio que se verifica entre democracia y Constitución (democracia constitucional). En este contexto de problematización, la articulación entre democracia política y democracia constitucional será "la luz" (enfoque o perspectiva) bajo la cual se analizará el umbral de expansión democrática.

Partiendo de la base que la investigación científica es "el perenne tránsito de un saber dado a un saber superior progresivo, mediante la aprehensión dialécticamente renovada de un saber adicional" (BASCUÑÁN VALDÉS: 1971), esta se debe encaminar dentro de un determinado proceso, que es obviamente extensivo a la investigación jurídica. En este contexto, se seguirá la estructura que propone el profesor Álvarez UNDURRAGA (2005), el cual ha seguido, entre otros, a los siguientes autores: Hernández Sampieri (1999), Fix-Zamudio (1995), Witker (1994), Jáñez Barrio (1996) y Ponce de León Armenta (1996). Distinguiéndose cuatro grandes acápites: el problema, el marco teórico, el marco metodológico y la bibliografía.

\section{El Problema}

\subsection{Planteamiento del problema}

Para comprender la delimitación del problema investigativo propuesto, se debe partir indicando que el término desarrollo alude al análisis diacrónico de la sociedad chilena, la cual se entiende como sociológicamente conceptualizada. A su vez, democracia política y democracia constitucional aluden a un ente o entidad-democracia- que se manifiesta 
de dos modos o formas, referentes ellas a la política y a la Constitución, respectivamente. Hay que señalar, además, que la democracia, en cuanto término y/o concepto común a democracia política y democracia constitucional, es, asimismo, un término con que se expresan diversos conceptos unidos entre sí por la analogía, sea esta metafísica o metafórica y, así, se habla de -y se define como- "un estado de espíritu", "un ideal", "un tipo de gobierno", "una ideología", "una filosofía", "una forma de vida" ("la filosofía democrática"), etc.

De este modo, la referencia de esta propuesta es al desarrollo democrático, en este preciso sentido; pero, obviamente, todo el proyecto tiene como fundamento a la democracia, tomada esta en sus diferentes aspectos o momentos. De ahí que, en la investigación, como se verá, se emplearán diversas estrategias metodológicas que, de un modo multidisciplinario, implican la ciencia jurídica, la sociología jurídica, la filosofía jurídica y la filosofía política. Dentro de esta perspectiva, y tratándose de una propuesta que corresponde a un estudio de carácter teórico, se utilizarán principalmente los métodos sociológico, analítico, comparativo e histórico, según sea el caso, lo que, a su vez, será complementado con las conclusiones de trabajos desarrollados sobre la base del método empírico.

\subsection{Formulación del problema}

Se traduce en la siguiente pregunta de investigación:

¿Chile, no obstante ir encaminado a una democracia más plena, exteriorizaría un déficit en su sociedad política, teniendo en cuenta que el desarrollo democrático no solo abarca diversos comportamientos sociales (democracia política), sino que también comprende la relación entre democracia y Constitución (democracia constitucional)?

\subsection{Sistematización del problema}

Se considerarán las siguientes subpreguntas:

- La concepción doctrinal que distingue entre un concepto ideal y un concepto real de democracia, ¿cómo puede ser utilizada para constatar el grado de desarrollo democrático de una sociedad política?

- ¿De qué forma se proyecta el contenido de la democracia en la verificación del umbral o piso mínimo de democraticidad de un sistema?

- Teniendo en cuenta que algunos países han alcanzado un grado de desarrollo democrático más avanzado, ¿cómo se identifica su rango de intensidad democrática a la luz del umbral comparativo? 
- ¿Cómo ha sido la evolución del sistema democrático chileno, especialmente a partir del proceso de transición actualmente en curso?

- ¿De qué modo se determina el significado político de la democracia, y cómo lo político que de ella emana legitima -como categoría jurídica- el texto constitucional, particularmente teniendo presente las diversas reformas que ha sido objeto la Carta Fundamental?

- ¿Qué mutaciones ha sufrido el concepto de ciudadanía -como indicativo del desarrollo democrático- a la luz del fortalecimiento del binomio democracia/derechos humanos?

- ¿Qué grado de vinculación existe entre democracia y desarrollo, teniendo en cuenta la influencia de los sistemas económicos en el desarrollo de las instituciones democráticas?

- ¿Cuál es el nuevo rol que desempeña la democracia en el orden jurídico internacional, y de qué forma legitima el orden jurídico de los países?

- ¿Cuáles son las implicancias en el régimen constitucional interno de la llamadas "cláusulas democráticas"?

\subsection{Objetivos de la investigación}

Los propósitos por los cuales se hace la investigación son los siguientes:

\section{a. Objetivo general}

Verificar el actual umbral o grado de desarrollo democrático de la sociedad chilena, lo cual implica analizar no solo los comportamientos político-sociales sino también el sistema jurídico-constitucional que actúa como vector.

\section{b. Objetivos específicos}

- Revisar la concepción doctrinal que distingue entre un concepto ideal y un concepto real de democracia, esto es, por un lado, la democracia como postulado ético que se aspira a conseguir y, por el otro, la forma de gobierno concreta que regula la convivencia de una sociedad en particular.

- Traducir el contenido de la democracia, a fin de reconocer los criterios necesarios e indispensables para medir el grado de democraticidad de un sistema, con que se proyecta verificar el umbral mínimo democrático de una sociedad política. 
- Describir los rasgos político-sociales de algunos países que han alcanzado un grado de desarrollo democrático más avanzado, a fin de identificar su rango de intensidad democrática, el cual ya no se mide solo desde la perspectiva del umbral mínimo, sino también se establece un umbral comparativo de democratización.

- Analizar la evolución histórica del sistema democrático chileno, especialmente desde 1989 en adelante, a fin de precisar los avances y retrocesos sufridos en esta materia.

- Explicar la relación existente en el binomio democracia/Constitución y de qué forma la democracia se manifiesta como principio legitimador de la Constitución, esto es, se pretende determinar el significado político de la democracia y cómo lo político que de ella emana legitima -como categoría jurídica- una Constitución democrática.

- Precisar las mutaciones que ha sufrido el concepto de ciudadanía a la luz del fortalecimiento del binomio democracia/derechos humanos.

- Indagar las relaciones entre democracia y desarrollo a partir de investigaciones empíricas basadas en los métodos cuantitativo y/o cualitativo, a fin de establecer la influencia de los sistemas económicos en el desarrollo de las instituciones democráticas.

- Estimar el nuevo rol que desempeña la democracia -como verdadera ética universal- en el orden jurídico internacional, particularmente en lo relativo a la fuerza obligatoria del principio de legitimismo democrático y el afianzamiento del concepto de "gobernabilidad democrática".

- Investigar las implicaciones de la inserción de "cláusulas democráticas" o "cláusulas de buena gobernanza" en los tratados ratificados por Chile, a fin de establecer el alcance de las obligaciones internacionales asumidas por el Estado chileno y evaluar su cumplimiento mediante su contraste con el régimen constitucional interno.

\subsection{Justificación de la investigación}

El tema del desarrollo democrático chileno no ha sido tratado con la debida profundidad, especialmente desde la perspectiva de la ciencia jurídica. Existen trabajos destacados en otras disciplinas, tales como la ciencia política o la historia, pero subsiste una total nebulosa respecto al modo en que interactúa la democracia política con la democracia constitucional, en cuyo contexto postulamos que se exterioriza un déficit en el grado de desarrollo democrático de nuestra sociedad política.

Este problema parte de la base de que existe un déficit democrático en la sociedad política chilena. Se es consciente de que esta premisa, en un principio, podría cuestionarse de "subjetiva", por tratarse solamente 
de la opinión de los investigadores que plantean esta propuesta, acerca del grado de democracia que existe en nuestro país. Sin embargo, existen diversas mediciones objetivas y estudios en torno a esta problemática, que sí nos inclinan a aceptar una significación de la democracia que pone en evidencia dicha carencia (Informe sobre Desarrollo Humano, 2002: Profundizar la democracia en un mundo fragmentado). Esto quiere decir que la democracia en Chile presenta un déficit no solo en tanto régimen de gobierno, sino también como forma de convivencia social (Informe sobre Desarrollo Humano en Chile, 2004: Democracia, Desarrollo Humano y Representación). Además, si lo miramos desde la perspectiva latinoamericana, se constata un patrón común en sus países, cual es, la existencia de profundas desigualdades en nuestra región. Asunto que ha propiciado una distancia histórica entre el Estado y los diversos componentes de la ciudadanía, que "parece haberse debido a dos procesos cercanamente conectados: primero, la ostensible influencia, como insumos de políticas públicas, de intereses sobre los cuales no es fácil argumentar que contribuyen a aspectos del bien común; y segundo, la actitud pasiva, sino obediente, que han exhibido varios gobiernos frente a la globalización económica y financiera" (O’DONNELL: 2004).

En Chile, asimismo, es particularmente importante lo concerniente al contenido de la democracia constitucional, pues se proyecta y permite verificar el grado de desarrollo democrático de nuestra sociedad. Destacándose la falta de articulación que se constata entre la democracia política y el postulado constitucional, lo que se traduce en que no existe $-o$ no se sabe si existe- una vinculación entre los comportamientos político-sociales y el sistema jurídico-constitucional; es decir, existe una brecha entre realidad y marco normativo. Circunstancia que impediría, entre otros asuntos, el pleno ejercicio y goce de la democracia, y limitaría ostensiblemente la significación de la soberanía del pueblo como principio legitimador del texto constitucional. Asunto que tampoco fue corregido por las reformas constitucionales de 2005 .

\section{El MARCo TEÓRICo}

\subsection{Antecedentes de la investigación}

Partiendo del antecedente de que la democracia es la única forma de organización política de las sociedades con capacidad de aprender y transformarse a sí misma sin perder sus atributos fundamentales, existe un apoyo universal respecto de ella, que, sin embargo, se ha transformado en un desacuerdo general sobre su significado (HunTINGTON: 1989). En efecto, en la literatura general y de ordinario, se le da a la palabra "democracia" el sentido de régimen político y, en la literatura 
especializada, suele decirse lo mismo, agregando eventualmente que eso es, ante todo, la democracia. Así -por ejemplo- J. R. PenNock (1971) advierte que tanto la etimología como la historia sugieren que el significado primario de "democracia" remite a una forma de gobierno. De un modo parecido, A. Ross (1989) observa que todo el campo semántico cubierto por la democracia se centra en el concepto de democracia política, añadiendo que, sentado esto, puede definirse a la democracia como una norma de vida. A su vez, G. SARTORI (1968) indica que el término "democracia" se refiere o a un sistema político, o a un conjunto de ideas, con la advertencia de que después de la Segunda Guerra Mundial, "democracia" llegó a ser usado como término honorífico universalmente, ampliándose tanto su significado hasta convertirse en un epíteto vago, hasta tal punto que, se ha dicho (B. DE Jouvenel), su discusión resulta intelectualmente nula, pues ya no se sabe de qué está uno hablando. El único remedio es, entonces, comenzar por definir. P. Schmitter y T. KARL -se ha dicho- tienen toda la razón para afirmar que hay que aclarar el significado de la palabra "democracia" si queremos darle algún uso en el análisis político; y, glosando lo anterior, se agrega que dicho aserto cobra especial valor tratándose de analizar problemas como los de la democratización o del desarrollo democrático (DoH CHULL SCIN: 1994).

Por ello preguntarse ¿qué es la democracia?, más que un simple interrogante, se está frente a toda una problemática, a la cual se adhieren una serie de cuestiones conexas (Bustos: 1991). Así, por ejemplo, al ser la democracia un término polivalente con el cual se pueden designar muchas cosas, desde el punto de vista de la semiótica, el significante está constituido por el término democracia, en cambio, el significado es de carácter mental: es el concepto o idea que conlleva el significante; la relación que une a ambos elementos (significante y significado) se denomina significación (Bustos: 1988). Por esta razón -desde una perspectiva pragmática-, el uso que un sujeto haga del término democracia dependerá, además, de las condiciones de ese uso, y entre estas y en primer lugar, de la situación existencial de dicho sujeto; de ahí que, por definición, el demócrata dispondrá, para su análisis de la democracia, de un approach esencialmente diferente del que no lo es (Bustos: 1988). De modo que, lógicamente, se podrá hablar tanto de un concepto democrático de la democracia como de un concepto no-democrático de la democracia; todo dependerá de dónde proviene dicho concepto: si de una mente inmersa, o no, en ese estado de espíritu en que consiste la democracia, de acuerdo a uno de sus conceptos o definiciones (Bustos: 1988).

Dentro de este contexto, si se discute el valor de la democracia como idea, la pregunta a formular es si se "ha comprendido con toda precisión qué es y significa la democracia; así se descubrirá si efectiva- 
mente se habla de los mismos hechos y si el interlocutor comprende plenamente qué efectos se siguen de ellos según sean las concepciones. Las tesis mismas no pueden ser discutidas, pero la comprensión de los hechos, que son supuestos de esas tesis, sí pueden serlo (...) Por ende, la elucidación científica del problema del valor de la democracia solo puede consistir en aclarar cuáles son las consecuencias significativas que la democracia implica para la vida de los seres humanos" (Ross: 1989). En este sentido cabe plantear el siguiente interrogante: ¿Es la democracia que tenemos la democracia a que aspiramos? Contestando a esta pregunta se señala por algunos autores que "puede tener dos respuestas, a saber, que la democracia limitada que tenemos es la democracia a que aspiramos, o que la democracia limitada que tenemos no es la democracia a que aspiramos"; valer decir, la respuesta va a depender de que se acepte una u otra opción, esto es si las limitaciones a nuestra actual democracia nos parecen bien o nos parecen mal (SQuella: 2000).

Esta cuestión conceptual, asimismo, no es un tema menor en Chile, pues todavía los partidos políticos representativos en el Congreso son herederos de la correlación de fuerzas nacida en el anterior régimen autoritario; de ahí que existan defensores de distintas concepciones democráticas (CAzor: 2002).

Ahora bien, respecto a los antecedentes de la relación entre Estado constitucional y democracia, el Estado como forma política ha evolucionado desde la época moderna hacia un Estado de Derecho constitucional y democrático. Por ello se dice que el factor predominante en nuestro tiempo es que la teoría de la Constitución tiende a ocupar de manera cada vez más intensa el lugar que antes dominó la teoría del Estado (Rubio Llorente: 1997). En este sentido, desde la perspectiva del jurista, Constitución se identifica con orden jurídico concreto, con ordenamiento que "constituye" al Estado, que lo crea como entidad jurídica (RUBIO LlORENTE: 1996); por esta razón se dice que la Constitución es la expresión jurídica del orden político estatal. Constitución que además posee una naturaleza normativa o deontológica (es decir, vinculada con el deber ser), por que no es otra cosa que la norma básica o fundamental llamada a regular el proceso político, constituyendo al Estado como entidad jurídica. En definitiva, será el Derecho el que, por vía de la Constitución, defina y constituya al Estado.

El constitucionalismo y la democracia se combinan para formar un sistema de gobierno conocido bajo el nombre de democracia constitucional; futuros historiadores descubrirán las últimas décadas del siglo XX como la era en la cual el ideal de la democracia constitucional se extendió rápidamente en el mundo (NiNO: 1997). En efecto, durante el siglo $\mathrm{XX}$ se consolidó junto al Estado constitucional el Estado democrático. Donde la democracia, como manifestación de la soberanía del pueblo como categoría legitimadora, es insoslayable al Estado constitucional. 
Dicho en otros términos, el principio democrático, que es una noción esencialmente política, también actúa como categoría jurídica que legitima el ordenamiento constitucional. Esto quiere decir que no hay democracia sin Constitución, ni Constitución sin democracia, pues un genuino Estado constitucional siempre debe ser un Estado democrático. En consecuencia, no hay otra Constitución que la Constitución democrática (Rubio LloRente: 1997).

Al respecto, conviene también mencionar que del punto de vista de la norma el Estado es un ordenamiento jurídico y del punto de vista del poder el Estado es la institucionalización del poder. De ahí que el Estado utilice la norma como herramienta y, a su vez, la norma utilizada por el Estado debe controlar el poder, y este debe encontrarse supeditado por la norma y al servicio del Derecho. Dicho en otras palabras, el Derecho como elemento constitutivo del Estado no es sino la limitación jurídica del poder político-estatal (Bustos: 2002). En este contexto poder y Derecho son dos de los elementos del Estado, cuya relación es determinante en una sociedad estatal democrática. Del mismo modo, cabe tener presente que, si bien es cierto que la Constitución es, ante todo, norma jurídica, toda vez que la teoría de la Constitución no puede ser más que una teoría jurídica (ARAGÓN: 1998). No hay que olvidar, asimismo, el significado político de la Constitución, esto es, como la más relevante expresión jurídica de un régimen político, de modo que este le da sentido a aquella (y, a su vez, la Carta Fundamental constituye la garantía jurídica del sistema político) (Bustos: 1989). Esta relación entre lo político y lo jurídico que se plasma en la Constitución, trae como resultado que la teoría jurídica, por sí sola, no basta para conocer dicha norma, es decir, para comprender lo que tiene (y por qué) de singular en el ordenamiento. De esta forma, la reflexión sobre el contenido de la Constitución, además de ser una reflexión eminentemente jurídica, no puede olvidar la trascendencia política, es decir, la pretensión de legitimación que la Constitución encarna por esa vía, y aquí el principio democrático juega un rol esencial. En el mismo sentido se ha dicho lo siguiente: "La idea de Estado de derecho exige que las decisiones colectivamente vinculantes del poder estatal organizado a que el derecho a de recurrir para el cumplimiento de sus propias funciones, no solo se revistan a la forma de derecho, sino que a su vez se legitimen ateniéndose al derecho legítimamente establecido" (Habermas: 1998). Es decir, el Derecho no se basta a sí mismo, sino que requiere de legitimidad; asunto que se ve muy claro en el plano constitucional, pues la legitimidad de la Constitución no solo depende de razones jurídicas, sino también políticas, como acontece con su vinculación con el principio democrático.

De lo dicho se desprende que en toda sociedad estatal se da una relación de regulación entre la norma y el poder; pero no cualquier tipo de relación, sino -como ya se ha adelantado- una relación dentro del 
contexto de una sociedad estatal democrática. La norma a que se hace referencia no es otra que la Constitución, cuya vinculación con el principio democrático es esencial para que se pueda hablar, con propiedad, de un Estado constitucional y democrático de Derecho. Aspiración ineludible de toda sociedad moderna. En consecuencia, no se puede excluir que exista un vector común en el que confluyen postulados de la democracia y del Estado de Derecho, y en virtud del cual ambos se encuentran engranados; de ahí que entre democracia y Estado de Derecho exista una afinidad (BÖCKENFÖRDE: 2000).

Por ello, dentro de la categoría de Constitución democrática, democracia y Constitución son conceptos que se generan y complementan. Abordar esta relación significa hacer frente a lo que la doctrina ha denominado como teoría constitucional de la democracia, esto es, la democracia como principio legitimador de la Constitución, es decir, la soberanía del pueblo como categoría jurídica (ARAgón: 1989). Sin embargo, la concepción de la democracia no solamente es una categoría jurídica, sino también una noción política; cuestión que lleva a analizar el significado de la democracia y su contenido, es decir, los criterios que se requieren para medir la democraticidad de un sistema. Todo lo cual, en última instancia, lleva a desentrañar el significado político de la Constitución y cómo lo político encarna la pretensión de legitimidad en una Constitución democrática.

\subsection{Bases teóricas de la investigación}

La problemática que se abordará requiere, por su propia naturaleza, de un enfoque multidisciplinario, que abarca la perspectiva de la ciencia jurídica, sociología jurídica, filosofía jurídica y filosofía política, pues el propio significado político-jurídico de la democracia así lo exige. Dentro de esta premisa, se partirá analizando la cuestión de la democracia política, para luego abordar el problema de la democracia jurídica, que tiene su máxima expresión en la democracia constitucional. Todo lo cual se enfocará, en el contexto propio del desarrollo democrático de la sociedad chilena.

\subsubsection{La democracia como expresión política: contenido y umbrales democráticos}

En cuanto al contenido de la democracia, esta (obviamente referida a la democracia real) debe reunir determinados requisitos para que el sistema político posea la condición de democrático. Para ello se pueden distinguir dos tipos de criterios: el relativo al método (es decir, el cómo de la democracia); y el concerniente a los fines (esto es, el qué de la democracia). 
Hay autores que plantean un determinado método para la democracia. Donde se manifiesta que la democracia es, principalmente, un "método político" y no puede constituir un fin en sí misma. Que se traduce en un conjunto de reglas a través de las cuales se crean determinadas formas de convivencia democrática; vale decir, se trata de una democracia procedimental formal (v. gr., elecciones periódicas, aplicación del juego de las minorías y mayorías), que excluye cualquier elemento valorativo o finalista. En otras palabras, se considera que el principal acuerdo de los ciudadanos está en torno a ciertas reglas del juego y no una comunidad de valores, ya que cada ciudadano tiene valores distintos que persigue individualmente (SCHUMPETER: 1968). Por ello, algunos autores sustentan que la democracia es, ante todo, un sistema de gobierno y, como tal, inseparable de la necesidad de que exista un poder público constituido y eficiente (BARros: 1987).

Esta tesis plantea el siguiente silogismo: método y fin son compartimentos estancos; lo que sería erróneo. Ya que método y fin están inexorablemente conectados, es decir, no cabe un método sin unos fines que los justifiquen; de ahí que la democracia no solo es un método sino también resultado. Trasladando la cuestión a términos jurídico-constitucionales, para que una Constitución sea democrática no es suficiente que haya sido emanada democráticamente; resulta imprescindible que también establezca un Estado democrático, es decir que su contenido material, sus fines, resulten democráticos (JÁuregui: 1995). Por esta razón, para otros autores la democracia, además del método, debe considerar determinados aspectos materiales (DAHL: 1999), más propios de una democracia procedimental sustancial, a fin de determinar si se ha establecido un sistema de democracia política o poliarquía (DAHL: 1992).

Dentro de los diferentes enfoques referidos al contenido de la democracia y sus respectivos umbrales (mínimo y comparativo), cabe destacar, entre otros, los desarrollados por la doctrina europea y norteamericana. Donde se distingue - considerando su naturaleza bifronte- entre un concepto ideal y un concepto real (VALLESPíN: 1999; DAHL: 1999), que parten, por un lado, de una determinada naturaleza normativa, es decir, la democracia es un ideal cargado de valores como justicia, igualdad, seguridad, decencia; pero, por el otro, tiene una determinada plasmación real o empírica, necesaria, a su vez, para saber como son sus diferentes manifestaciones concretas. Dicho en otros términos, existe un: a) concepto ideal (como sujeto): en este sentido la democracia es un ideal o conjunto de valores que expresan las aspiraciones de igualdad y libertad de los seres humanos, vale decir, como un postulado ético donde el pueblo se constituye en sujeto del poder (se trata de una concepción no estrictamente política); b) concepto real o práctico (como objeto): este ideal (Democracia con mayúscula), a su vez, se plantea en la práctica como un modelo o forma de gobierno denominado sistema 
democrático (democracia con minúscula), vale decir, un modelo de regulación de la convivencia política de una sociedad concreta, que se manifiesta en una serie de normas, instituciones y actividades políticas (JÁUREGUI: 1995).

Ambos conceptos no son antagónicos, ni mucho menos, sino que es necesario considerarlos en una relación de simultaneidad. Ya que "el logro del ideal democrático resulta tan imposible como imprescindible su búsqueda permanente" (JÁuREGUI: 1995); esto es, el concepto de democracia se debe necesariamente circunscribir dentro del binomio imposibilidadlimprescindibilidad (Michels: 1972), que, a su vez, determina una conexión entre la Democracia ideal y la democracia real. La imposibilidad del logro del ideal democrático es un elemento imprescindible para la determinación y comparación de la democracia real. Con ello, por ejemplo, se ponen de manifiesto los hechos diarios, teniendo como referente el ideal ético-político de la democracia. El problema fundamental reside, de esta forma, en lograr una optimización de los ideales democráticos, sin renunciar a ellos, para deducir de ese modo el abismo entre la Democracia ideal y la democracia real. Es decir, la democracia no puede eludir estar en una permanente tensión entre utopía y adaptación (VAllespín: 1999).

Existen, asimismo, diversos umbrales o grados de desarrollo democrático. En efecto, se ha establecido un umbral mínimo de la democracia, el cual se traduce en los siguientes criterios fundamentales: a) libertades sustanciales: se exigen determinadas libertades mínimas, v. gr., libertad de información, expresión, etc.; b) forma de selección del poder político: elecciones libres y periódicas, igualdad del voto, igualdad de la representación, representación de las minorías y mayorías, etc.; c) organización y funcionamiento del propio sistema democrático: la ausencia de controles no democráticos externos o internos, el principio de mayoría, el principio de división de los poderes, independencia del poder judicial, el sometimiento de los poderes públicos y los ciudadanos al ordenamiento jurídico, etc. (JÁuREgUi: 1995). Del mismo modo, existen al menos cinco criterios que se deben necesariamente considerar en un gobierno democrático: Participación efectiva: todos los miembros del cuerpo político deben tener oportunidades iguales y efectivas para hacer que sus puntos de vista sobre cómo haya de ser la política sean conocidos por los otros miembros. Igualdad de voto: cuando llegue el momento en el que sea adoptada finalmente la decisión sobre la política, todo miembro debe tener una igual y efectiva oportunidad de votar; y todos los votos deben contarse como iguales. Alcanzar una comprensión ilustrada: dentro de límites razonables en lo relativo al tiempo, todo miembro debe tener oportunidades iguales y efectivas para instruirse sobre las políticas alternativas relevantes y sus consecuencias posibles. Ejercitar el control final sobre la agenda: los miembros deben tener la oportunidad exclusiva 
de decidir cómo y, si así lo eligen, qué asuntos deben ser incorporados a la agenda. De esta forma, el proceso democrático exigido por los criterios precedentes no se cierra nunca. Las políticas de la asociación están siempre abiertas a cambios introducidos por sus miembros, si estos así lo deciden. Inclusión de los adultos: todos o, al menos, la mayoría de los adultos que son residentes permanentes, deben tener los plenos derechos de ciudadanía que están implícitos en los cuatro criterios anteriores. Antes del siglo XX este criterio era inaceptable para la mayoría de los defensores de la democracia (DAHL: 1999).

La democracia, además de su umbral mínimo, también debe establecer un umbral comparativo de democratización, que consiste en una gradación de la intensidad democrática entre los países que han alcanzado un grado de desarrollo democrático más alto, con respecto a los niveles de democraticidad alcanzado en la mayoría de los otros sistemas políticos. Cuando la gradación se modifica o avanza se debe alterar el umbral mínimo, es decir, se eleva el listón del umbral mínimo (de modo que los sistemas que no hayan alcanzado ese nuevo nivel dejan de ser considerados como democráticos). En este sentido, por ejemplo, para la actual democracia española, a fin de establecer un eficaz índice de su democraticidad, es más útil el criterio del umbral comparativo. Al contrario, para el régimen chileno actual posee una total relevancia el criterio del umbral mínimo, más que el comparativo. De esta forma, según sea la realidad específica que se analiza, distinto será el parámetro en la determinación del nivel de democratización. Por ello, la columna vertebral de un modelo de democracia es lo que se ha denominado como "principio de justificación", esto es, aquello que proporciona un significado diferenciado de cómo se entiende la democracia (HeLD: 1992).

Se debe mencionar, igualmente, que en los innumerables estudios que hoy se dedican a la democracia, hay una cierta división del trabajo que se origina, precisamente, a partir de las dimensiones anteriormente analizadas. En efecto, un extenso número de teóricos, armados de una creciente sofisticación metodológica, desmenuzan y comparten las distintas variedades de la democracia dentro y entre diferentes áreas geográficas; especifican las peculiaridades de cada proceso de transición y las condiciones de la consolidación de la democracia; ponderan también las distintas variables que favorecen o empecen el desarrollo y asentimiento de la democracia, particularmente lo referente a la llamada democracia global (HABERMAS: 1995; Cauffignal: 1992; Sartori: 1998; Dahl: 1994; BobBio: 2000; Touraine: 1995; JÁuregui: 2000; GINER: 1998; Hermet: 1995; además cabe destacar a BeCK: 1998; CAMPS: 1997; FuKuYama: 1989; Held: 1995; Kelsen: 1988; Huntington: 1997).

No menos importante en esta última materia, se han vuelto las relaciones entre, por un lado, democracia y derechos humanos y, por otro, democracia y desarrollo económico. Ambos binomios dan cuenta 
de un cambio de paradigma que importa pasar de la democracia electoral (como forma de gobierno) a la democracia centrada en los ciudadanos. Este cambio de perspectiva ha permitido, inclusive, la acuñación de un nuevo derecho humano: el derecho a la democracia (RoDríguez PALOP: 2002). Este tránsito ha sido catalizado, entre otras cosas, por el robustecimiento de la noción de "ciudadanía social" que no es otra cosa que la categoría jurídica construida a partir del principio de interdependencia, indivisibilidad e integridad de todos los derechos humanos (Declaración y Programa de Acción de Viena, 1993). En esta perspectiva, la democracia excede a un método para elegir a quienes gobiernan; es también una manera de construir, garantizar y expandir la libertad, la justicia y el progreso, organizando las tensiones y los conflictos que generan las luchas de poder. Esta mutación obedece al surgimiento de nuevas exigencias o pulsiones a las que están sometidos los sistemas democráticos y que generan fuertes problemas de legitimación de los mismos. Habermas ha explicado este fenómeno de la siguiente manera: Existe una relación de equilibrios sensible entre el sistema económico y el sistema político que se traduce en que el Estado se convierte en una suerte de órgano ejecutor de la ley del mercado. Esto trae aparejado que, paradójicamente, los problemas de legitimación del capitalismo tardío no puedan ser subsumidos bajo un imperativo generalizado de autoconservación, puesto que no pueden resolverse sin referencia a la satisfacción de necesidades legítimas - la distribución de los valores en uso- mientras que los intereses de la valorización del capital proscriben, justamente la consideración de aquellas. Esta paradoja se perpetúa, a su vez, porque los sistemas políticos actuales trasladan las responsabilidades básicas a los individuos (clientes-consumidores), quienes deben tomar decisiones en condiciones de complejidad creciente y racionalidad imperfecta (HABERMAS: 1999).

Los nuevos retos que deben enfrentar las democracias contemporáneas pueden resumirse en la exigencia de crear "equilibrios virtuosos". Esta pulsión es la que ha determinado el desarrollo del concepto de "gobernabilidad democrática". La gobernabilidad viene a ser una cualidad de las sociedades para autogobernarse democráticamente enfrentando exitosamente los retos de satisfacción de necesidades de toda índole que se demandan endógenamente. Es decir, es la habilidad del gobierno y de los distintos sectores sociales para combinar adecuadamente en un período dado tres grandes aspiraciones que han calado profundamente en la cultura cívica de esta época: un crecimiento económico dinámico basado en el mercado, márgenes satisfactorios de equidad, igualdad de oportunidades y protección social, y grados crecientes de participación ciudadana en las decisiones políticas (TomassinI: 1996). En otras palabras, la gobernabilidad viene a ser la expresión institucional del problema de la legitimación del poder. 
Así las cosas, la democracia ha dejado de ser considerada como un reducto político-jurídico para transformarse en un aspecto crucial para el desarrollo económico como lo viene demostrando el Programa de Naciones Unidas para el Desarrollo (PNUD) a través de sus diversos Informes sobre Desarrollo Humano. En el sentido inverso (aunque no excluyente) diversos estudios han demostrado que el desarrollo está relacionado con la democracia porque tiende a generar cambios sociales y culturales que contribuyen al surgimiento y florecimiento de la democracia. Tanto es así -suele afirmarse- que la democracia no conduce per se al desarrollo. Lo anterior porque la satisfacción con la propia vida en general conduce a la legitimidad política mucho mejor que la opinión favorable del sistema político. Es decir, la dirección causal parece ir más desde los factores económicos hacia las instituciones que a la inversa. Dentro de este marco, uno de los aspectos que ha suscitado una atención privilegiada es el relativo a la conexión entre la igualdad de la renta y la estabilidad de la democracia. A este respecto, INGLEHART ha señalado que niveles muy altos de desigualdad de renta conducen a una política extremista en la que los desposeídos no tienen nada que perder y sí mucho que ganar con un cambio radical, mientras que la elite privilegiada está enormemente interesada en mantener el statu quo a cualquier precio. Por el contrario, un grado razonable de igualdad de la renta genera un espíritu de compromiso y moderación crucial para la política democrática puesto que la democracia transfiere poder político al público, permitiéndole presionar a favor de políticas sociales más igualitarias (INGLEHART: 1998). Por su parte, los estudios en el ámbito de la psicología social han demostrado que los factores culturales son una variable explicativa fundamental de los sistemas políticos. Así por ejemplo, tanto el individualismo como el colectivismo son formas de sociabilidad que se definen por la preeminencia de determinados valores en el semblante social. Dichos valores se han plasmado como herencia de cambios religiosos, económicos y políticos que, a su turno, han dado origen a patrones diferenciados de existencia social. Entre estos valores puede citarse la solidaridad, la independencia, la benevolencia, etc. (Gouveia: 2003). Es cierto que estos valores se han traslado al Derecho formando una especie de "ética pública" pero no lo es menos que estos bosquejos sociales condicionan el diseño y el rol de los Estados, del sistema económico y del sistema jurídico. Por ejemplo, mientras más débil es el individualismo en el software mental de los ciudadanos, mayor es la probabilidad de que el Estado desempeñe un papel dominante en el sistema económico. De otro lado, cuanto más individualistas son los ciudadanos de un país, menor es la probabilidad de que su libertad de prensa sea coartada por las autoridades (HOFSTEDE: 1999).

Resulta ingenuo, entonces, creer que los cimientos de las instituciones democráticas descansan única y exclusivamente en procla- 
maciones formales de libertad e igualdad. El hecho de conceder una igualdad política oficial no basta para crear, en la misma medida, la voluntad o capacidad de participar en los procesos políticos, ni una capacidad igual en todos de influir en los resultados (PNUD: 2002). La promoción de políticas democráticas requiere mucho más. Implica ampliar las capacidades de los individuos para conseguir funcionamientos valiosos garantizando a través de ello el ejercicio pleno de sus libertades (SEn: 1998; Nussbaum: 2002). Por tanto, requiere hacer posible que las personas desempeñen un rol más activo fomentando, particularmente, el desarrollo de los colectivos en desventaja (mujeres, grupos minoritarios, etc.) y generando canales y vías extraoficiales a fin de que las instituciones democráticas puedan representar mejor a los ciudadanos. Ya el Informe sobre Desarrollo Humano de 1990 destacaba como tercer pilar de la estrategia para el Desarrollo Humano del siglo XXI: promover la participación mediante la gestión democrática de los asuntos públicos.

La multidimensionalidad de la democracia a la que nos hemos referido previamente, no ha pasado inadvertida en el ámbito del Derecho Internacional. El contenido semántico de la voz "democracia" en el espectro normativo internacional se articula sobre la base de la unión indisoluble entre derechos humanos, desarrollo económico y gobernabilidad (Vid. Resolución de la Comisión de Derechos Humanos, sobre la promoción de un orden internacional democrático y equitativo, E/CN.4/RES/2002/72). Así, por ejemplo, la relación entre la democracia representativa y la vigencia de los derechos humanos ha sido reafirmada en varias reuniones de consulta, conferencias interamericanas, protocolos adicionales, resoluciones de la Asamblea General de la Organización de los Estados Americanos, y por los órganos de control de la Convención Americana sobre derechos humanos (Vid. Informe Comisión Interamericana de Derechos Humanos $N^{o}$ 137/99, Caso 11.863 Andrés Aylwin Azócar y otros [Chile], 27 de diciembre de 1999).

En este contexto, la Carta Democrática Interamericana (suscrita por Chile) orienta su objetivo principal al fortalecimiento y preservación de la institucionalidad democrática, elevándola a la categoría de esencial para el desarrollo social, político y económico de los pueblos de las Américas. Por otra parte, desde 1992, la Unión Europea viene incluyendo en todos sus acuerdos con terceros países una cláusula según la cual el respeto de los derechos humanos y de la democracia es un "elemento esencial" de las relaciones internacionales (Vid. Informe de la Comisión Europea sobre la aplicación de medidas para promover el respeto por los Derechos Humanos y los principios democráticos en las relaciones exteriores durante el periodo 1996-1999, Bruselas, 14.11.2000, COM (2000) 726 final). Dicha cláusula, denominada "cláusula democrática", estipula que las relaciones entre las partes, así como todas las disposiciones del 
propio acuerdo, deben basarse en el respeto de los derechos humanos y de los principios democráticos, que inspira las políticas nacionales e internacionales de las partes y constituye un elemento esencial del acuerdo. Dentro de este ámbito se circunscribe el apartado, del Acuerdo de Asociación celebrado entre Chile y la Unión Europea, dedicado al diálogo político, cuyo contenido esencial fue aceptar por parte de los negociadores la llamada "cláusula democrática" (Loughlin: 1999; Prats: 2002). El desarrollo de esta cláusula, sin duda, ha tenido una particular incidencia en las relaciones internacionales del Estado chileno y, por tanto, su contraste con el régimen constitucional interno es indispensable para una mejor comprensión de este último. En este contexto, por ejemplo, se plantea la necesidad de definir el alcance de la cláusula democrática -en la esfera interamericana- a la luz de limitaciones que han surgido a partir de la consolidación de democracias insuficientes (MÉnDEZ: 2000). Desde luego, esta evolución normativa aporta una nueva gama de elementos para interpretar el principio de legitimismo democrático en el Derecho Internacional cuya fuerza vinculante tradicionalmente ha sido objeto de controversia (FERNÁndez LIESA: 1997).

\subsubsection{La democracia como expresión jurídica: Estado constitucional $y$ desarrollo democrático de la sociedad chilena}

El tema de la democracia no es un asunto reciente en Chile. Desde los inicios de la República, en el siglo XIX, la "fiebre de democracia", cuyo parámetro central fue la experiencia de los Estados Unidos, era un tema candente que se miraba, por algunos, como una virtuosidad intrínseca que podía trasplantarse a las tierras de la América hispana (Eyzaguirre: 1976). Sin embargo, otros estimaban que en Estados Unidos el ideal democrático podía funcionar bien, ya que era fruto de un proceso evolutivo; así, por ejemplo, Diego Portales llegó a decir que "la democracia que tanto pregonan los ilusos es un absurdo en países como los americanos, llenos de vicios y donde los ciudadanos carecen de toda virtud como es necesaria para establecer una verdadera república" (EYZAGUIRRE: 1976).

Este debate siguió desarrollándose durante toda la vida institucional chilena, donde es posible vislumbrar un permanente desacuerdo en torno a qué tipo de democracia se adhería, suceso que, hasta el día de hoy, sigue manifestándose con toda fuerza. Igualmente, esta cuestión se ha trasladado al campo de la legitimidad democrática de las dos Cartas Fundamentales que ha tenido nuestro país durante el siglo XX: la Constitución de 1925 y la de 1980 . Por cuanto la democracia, como categoría fundamentadora, siempre ha sido insuficiente al momento de establecer en Chile un real Estado constitucional y democrático. Circunstancia -como se verá- que, pese a las reformas constitucionales, aún 
subsiste. Particularmente destacable es la segunda mitad del siglo XX, donde las consecuencias de la política pendular de este período todavía se están viviendo en la actualidad. Algunos autores (BOENINGER: 1997) resumen muy bien esta idea: "Primero fue la "revolución en libertad" del gobierno democratacristiano de Eduardo Frei Montalva, luego la "vía chilena al socialismo" de la Unidad Popular, seguida por el golpe militar de 11 de septiembre de 1973 y diecisiete años de régimen autoritario presidido por el general Pinochet (...) Finalmente, tras una transición pacífica a la democracia, sorpresiva para muchos, el país es identificado internacionalmente como un modelo de éxito económico y político (...) Chile, ciertamente, no posee características culturales ni peculiaridad alguna que lo distinga como escenario lógico y probable de sucesivos experimentos políticos de tanta notoriedad. La explicación de lo que nos ha ido ocurriendo hay que buscarla en el conjunto de procesos, factores y circunstancias históricas internas y externas, políticas, económicas y sociales, incluida la dimensión cultural, cuya interacción produjo nuestra mutante realidad".

Con razón se ha dicho que la realidad constitucional de Chile parece vivir una contradicción, sintetizable en el contraste entre la consolidación de nuevos principios democráticos (garantía de los derechos fundamentales, pluralismo político, elegibilidad de los órganos político-representativos, etc.) y la dificultad que representa la inspiración no precisamente democrática de la actual Carta Política (Rolla: 2002).

Para nadie es un misterio que la Constitución de 1980 adolece de una clara falta de legitimidad democrática en su origen, por dos causas principales: es fruto de un constituyente autoritario y su aprobación se realizó mediante plebiscito que no cumplió los requisitos exigidos en un acto electoral democrático. Este origen espurio de la Carta Fundamental sigue estando presente y subyace en nuestra práctica constitucional. Cuyo alcance "impide entender la Constitución chilena en sentido jurídico, porque es cierto que sin democracia no se entiende el concepto jurídico de Constitución" (CARRILlo: 2002).

Desde la perspectiva de su contenido (legitimidad interna), si bien la reforma constitucional de 2005 desconfigura una serie de "enclaves" antidemocráticos o autoritarios (GARRETón: 1995; ARRIAGADA: 1986), que constituían el núcleo esencial de la idea de democracia protegida que imperaba (Reforma a la Constitución Política de la República: 2001), resulta difícil justificar -siguiendo a NiNO- el estricto carácter jurídico-político (normativo) de la Constitución, toda vez que no se trata de un Derecho (juridicidad constitucional) producido por un legislador-constituyente elegido democráticamente (caso de los senadores institucionales), y no hay razones epistémicas, o sea, razones para creer que la norma dictada (reforma constitucional) sea una derivación de un principio de moral válido, esto es, que refleje el principio demo- 
crático como principio legitimador, y, por ende, constituya un Estado democrático (BARBERIS: 2005). Aun a riesgo de sintetizar demasiado la argumentación, se podría igualmente concluir que tampoco existirían tales razones para creer que nuestro legislador-constituyente, en su conjunto, posea la suficiente justificación de legitimidad para transformar la Carta de 1980 en una Constitución normativa, toda vez que, precisamente, ha emanado del procedimiento establecido por una institucionalidad no auténticamente democrática; es decir, aún existe un consenso incompleto o pacto constitucional incompleto (SQUella: 2000). Asunto nada nuevo, por cuanto la mayoría de las transiciones desde regímenes no democráticos -especialmente autoritarios- a regímenes democráticos han sido procesos conducidos y orientados por las élites políticas, las que articularon demandas intraélite y en menor medida de las masas (OBANDo: 2001). Razón por la cual, en el régimen político chileno se habla de un predominio de los "arreglos institucionales contramayoritarios" (PEÑA: 2000).

Curiosamente para nuestra doctrina mayoritaria el tema de la Constitución democrática está resuelto, y sustentan tal conclusión en dos hechos esenciales: el plebiscito de 1989 (ANDRADE GEYwITZ: 1991) y la entrada en vigencia de las recientes reformas constitucionales. En efecto, para este sector, "el déficit de legitimidad de origen de la Constitución de 1980 fue subsanado por la participación libre y mayoritaria de la ciudadanía en el plebiscito de 1989", y con el fin de los enclaves autoritarios esta se democratiza y "encarna un consenso nacional" (Zapata Larraín: 2005; Carrasco Delgado: 2002). Al contrario, estimamos que todavía en nuestra sociedad política existe una clara falta de articulación entre la democracia política y el postulado constitucional. En este sentido, las reformas de 2005, han posibilitado que la Carta Fundamental, como nunca antes, sea un piso institucional compartido, que sin duda contribuye al desarrollo democrático. Sin embargo, esta conclusión habría que mirarla desde la perspectiva de su eficacia jurídico-formal y no precisamente de su legitimidad política. Además, esto plantea un concepto débil de "constitucionalismo", pues, como han sostenido algunos autores, la robustez del concepto de constitucionalismo depende del modelo particular de democracia que se tome y sus instituciones específicas (NINO: 1997).

\subsection{Hipótesis}

Partiendo de la base que dentro del paradigma del Estado constitucional es esencial la significación jurídica de la democracia, estableciéndose un nexo ineludible entre una categoría eminentemente política, como es la democracia, y una categoría eminentemente jurídica, como es la Constitución. Se postula que mientras no exista una más profunda y 
real articulación entre democracia política y democracia constitucional, no se logrará efectivamente alcanzar el umbral necesario de democratización en la sociedad chilena. Particularmente en la medida en que, entre nosotros, la democracia política trasmita sus valores -también políticos, entendiendo la democracia no solo como forma de gobierno sino también como forma de vida- a nuestra Constitución, incluyéndolos en ella bajo la forma de valores jurídicos, o, lo que es lo mismo, atendiendo a la correspondencia en que nuestra Constitución ha acogido, y expresado jurídicamente, los valores políticos de la democracia. Para sustentar esta propuesta se tendrán como parámetros los contenidos económico-sociales y constitucionales de algunos países que han alcanzado un grado de desarrollo democrático más avanzado.

De ahí que, por ejemplo, no baste en absoluto con reformar el texto constitucional, mediante un acuerdo político exclusivamente centrado - "desde arriba" - en la estructura institucional del poder constituyente derivado, si no pasa por un completo consenso constitucional, que implique al pueblo y lo haga partícipe de dicho proceso - "desde abajo"-, a fin de hacer posible una democracia más real y que supere el umbral necesario de democraticidad. Approach que interpretaría más íntegramente los componentes esenciales que se espera que tenga en un futuro próximo el Estado constitucional democrático chileno.

\subsection{Variables e indicadores}

\subsubsection{Variable independiente}

Articulación entre democracia política y democracia constitucional.

\section{Definición conceptual}

Existe un nexo ineludible entre una categoría eminentemente política, como es la democracia, y una categoría eminentemente jurídica, como es la Constitución; asunto que también pone de relieve el significado político -y no exclusivamente normativo- de la Carta Fundamental.

\section{Definición operacional}

En nuestro ordenamiento jurídico el principio democrático como regla estructural del Estado constitucional emana, principalmente, de los arts. $4^{\circ}$ y $5^{\circ}$ de la Constitución Política, que proclaman que Chile es una República democrática y hacen residir la soberanía nacional en el pueblo chileno y en los poderes constituidos. Asimismo, del art. $19 \mathrm{n}^{\circ} 15$, inciso $6^{\circ}$, se desprende que el ordenamiento fundamental se 
inspira en determinados "principios básicos del régimen democrático y constitucional", tales como la autodeterminación del pueblo, el respeto de los derechos humanos fundamentales y las diversas técnicas o procedimientos democráticos (donde se encuentran, entre otros, la garantía del pluralismo político y la plena vigencia del Estado de Derecho).

\subsubsection{Variable dependiente}

Umbral de desarrollo democrático de la sociedad chilena.

\section{Definición conceptual}

Tomado desde una perspectiva dinámica y progresiva, el parámetro del umbral democrático permite determinar el grado o índice de desarrollo de la sociedad chilena. Para ello, se considerarán no solo los aspectos procedimentales del Estado democrático sino también los materiales (método + fines), en especial la complementariedad que debe existir con el poder político-social de los ciudadanos y su capacidad de autodeterminación colectiva.

\section{Definición operacional}

Se trata de determinar las condiciones necesarias de un futuro régimen vitalmente democrático, tanto en lo político como en lo jurídico. Es decir, se espera como resultado, que el desarrollo democrático de la sociedad chilena se inscriba dentro de la perspectiva de una democracia más plena y viva ("desde abajo"), donde necesariamente hay que entender la democracia como un proceso evolutivo -no precisamente armónico- que requiere de la discusión y la controversia, para finalizar, eso sí, en el consenso o acuerdo.

\section{MARCo METOdOLÓGICO}

\subsection{Tipos y niveles de investigación}

El estudio se desenvolverá, principalmente, en el plano explicativo o causal, a fin de conocer por qué acontece el fenómeno del deficitario desarrollo democrático de la sociedad chilena, y cómo interactúa en este contexto la democracia política con la democracia constitucional. En este sentido, la presente indagación no puede prescindir de la consideración de la variable social, toda vez que existe una estrecha vinculación con la normativa constitucional, es decir, se trata de visualizar el Derecho como un conjunto normativo que cumple ciertas funciones 
sociales. La temática, además, se enmarcará dentro de una investigación jurídica documental, que analizará -como fuentes formales- textos de Derecho positivo, doctrina nacional y comparada, material jurisprudencial, resoluciones de organismos internacionales, registros contenidos en Internet, como también resultados y conclusiones a los que han arribado investigaciones desarrolladas sobre la base del método empírico.

\subsection{Métodos de investigación}

En esta investigación se emplearán las diversas estrategias metodológicas que, de un modo multidisciplinario, implican la ciencia jurídica, la sociología jurídica, la filosofía jurídica y la filosofía política. Dentro de esta perspectiva, y tratándose de una propuesta que corresponde a un estudio de carácter teórico, se utilizarán principalmente los métodos sociológico, analítico, comparativo e histórico, según sea el caso; lo que, a su vez, será complementado con las conclusiones de trabajos desarrollados sobre la base del método empírico.

Se utilizará, dentro del enfoque propuesto, el método sociológico, toda vez que la investigación se circunscribe en torno al desarrollo democrático, lo que implica un análisis diacrónico de la sociedad chilena, la cual se entiende como sociológicamente conceptualizada y proyecta una relación dinámica y dialéctica entre la variable social y la normativa constitucional. Del mismo modo, el enfoque propuesto analizará estudios que se han desarrollado sobre la base de reglas cuantitativas y/o cualitativas (método empírico). Eso permitirá llevar a cabo una explicación desde la perspectiva existencial de la democracia, debido a que, en gran parte, su significado depende de la situación concreta de la misma o, que es lo mismo, de los usos de ella. De esta manera, los contextos histórico, político y social son determinantes para lograr su entendimiento, y poder buscar, de esa forma, en el mundo real, las condiciones que serían necesarias y suficientes para lograr su maximización. Se valdrá, asimismo, del método analítico, cuya pretensión es examinar lógicamente el concepto, significado y expresión jurídico-política de la democracia. Igualmente, se empleará el método comparativo, por cuanto se tendrán como referentes los contenidos económico-sociales y constitucionales de algunos países que han alcanzado un grado de desarrollo democrático más avanzado, a fin de identificar su rango de intensidad democrática, el cual ya no se mide solo desde la perspectiva del umbral mínimo, sino también se establece un umbral comparativo de democratización. Finalmente, de manera coadyuvante, se empleará el método histórico, pues el origen y el desarrollo democrático de la humanidad se encuentra estrechamente vinculado con los elementos que han justificado y justifican en la actualidad este régimen político. 
Todos estos métodos, que tienen como parámetro esencial el enfoque multidisciplinario antes enunciado, se conectarán con el objeto principal de la investigación, cual es, verificar el actual umbral o grado de desarrollo democrático de la sociedad chilena, lo cual implica analizar, como ya se ha dicho, no solo los comportamientos político-sociales (democracia política) sino también el sistema jurídico-constitucional que actúa como vector (democracia constitucional).

\section{Bibliografía}

- AA. Vv.: Informe de la Comisión de Constitución, Legislación, Justicia y Reglamento del Senado evacuado el 6 de noviembre de 2001, reproducido en el volumen Reforma a la Constitución Política de la República de 1980, Valparaíso, Imp. del Senado, 2001.

- Aa. Vv..: Informe sobre Desarrollo Humano (PNUD), 2002: Profundizar la democracia en un mundo fragmentado.

- Aa. Vv.: Informe sobre Desarrollo Humano en Chile (PNUD), 2004: Democracia, Desarrollo Humano y Representación).

- Álvarez Undurraga, Gabriel: Curso de Investigación Jurídica, LexisNexis, Santiago, 2005.

- Andrade Geywitz, Carlos: Reforma de la Constitución Política de Chile de 1980, Editorial Jurídica de Chile, Santiago, 1991.

- Aragón, Manuel: Constitución y democracia, Tecnos, Madrid, 1989.

- Estudios de Derecho Constitucional, Centro de Estudios políticos y Constitucionales, Madrid, 1998.

- Arriagada, Genaro: Democracia en Chile, doce conferencias, Aa. Vv., Cieplan, Santiago, 1986.

- Barberis, Mauro: Neoconstitucionalismo, democracia e imperialismo de la moral, en AA. Vv. Neoconstitucionalismo(s), Trotta, Madrid, 2005.

- Barros, Enrique: "La democracia como forma del poder. Un enfoque normativo", Revista Centro de Estudios Públicos, $n^{\circ} 26$, 1987.

- Bascuñán Valdés, Aníbal: Manual de técnicas de la investigación jurídica, Editorial Jurídica de Chile, Santiago, 1971.

- BeCK, UlRich: ¿Qué es la globalización?, Paidós, Barcelona, 1998. La democracia y sus enemigos, Paidós, Barcelona, 2000.

- Bobbio, Norberto: Futuro de la Democracia, Fondo de Cultura Económica, México, 1993.

- "Democracia y sistema internacional", en Revista de Filosofía Politica, $\mathrm{n}^{\circ}$ 4, Madrid, 1994.

- Böckenförde, E. W.: Estudios sobre el Estado de Derecho y la democracia, Trotta, Madrid, 2000. 
- Boeninger, Edgardo: Democracia en Chile, Editorial Andrés Bello, Santiago, 1997.

- Bustos, Ismael: “¿Qué es la Democracia? (Un approach lógico-semántico para su definición)", en Anuario de filosofía jurídica y social, Edeval, Valparaíso, 1991.

“QQué es la Democracia? (Introducción al análisis semiológico del término)", en Anuario de filosofía jurídica y social, Edeval, Valparaíso, 1988.

- Camps, Victoria: "Ética del buen gobierno", en Aa. Vv., Buen gobierno y política social, Ariel, Barcelona, 1997.

- Carrasco Delgado, Sergio: Génesis y vigencia de los textos constitucionales chilenos, Editorial Jurídica de Chile, Santiago, 2002.

- Carrillo, Marc: "Las hipotecas de la Constitución chilena", en Revista de Estudios Políticos (Nueva Época), Madrid, $\mathrm{n}^{\circ} 115$, eneromarzo de 2002.

- Cazor Aliste, Kamel: "Democracia y Constitución en Chile", en Revista de Derecho, Facultad de Ciencias Jurídicas y Sociales, Universidad Austral de Chile, Vol. XI, diciembre de 2000.

"Constitución, principio democrático y reformas constitucionales", en Revista de Derecho, Facultad de Ciencias Jurídicas y Sociales, Universidad Austral de Chile, Vol. XIII, diciembre de 2002.

- Cortina, Adela: Ética aplicada y democracia radical, Tecnos, Madrid, 2001.

- Couffignal, Georges (compilador): Democracias posibles, Fondo de Cultura Económica, Buenos Aires, 1993.

- Dahl, Robert: Poliarquía, en Diez textos básicos de Ciencia Política, Ariel, Barcelona, 1992.

La democracia. Una guía para los ciudadanos, Taurus, Madrid, 1999.

- Doh Chull Scin: "En la tercera ola de la democratización", Revista Política Mundial, $\mathrm{n}^{\circ}$ 47, octubre de 1994.

- Elster, Jon y Slagstad, Rune: Constitucionalismo y Democracia, Fondo de Cultura Económica, México, 1999.

- Eyzaguirre, Jaime: Fisonomía Histórica de Chile, Edit. Universitaria, Santiago, 1976.

- Fernández Liesa, Carlos: "Democracia y Desarrollo en el Ordenamiento Internacional”, en MARIÑo MENÉNDEZ, F. y FERnÁNDEZ LiesA, C. (Eds.): El Desarrollo y la Cooperación Internacional, Universidad Carlos III-BOE, Madrid, 1997.

- Fix-Zamudio, Héctor: Metodología, docencia e investigación jurídicas, Porrúa, México, 1995.

- Fukuyama, Francis: El fin de la historia y el último hombre, Planeta, Barcelona, 1999.

- Garretón, Manuel Antonio: Hacia una nueva era política. 
Estudio sobre las democratizaciones, Fondo de Cultura Económica, Santiago, 1995.

- "La posibilidad democrática en Chile", en AA. Vv., Democracia contemporánea: Transición y Consolidación, Universidad Católica de Chile, Santiago, 1999.

- Giner, Salvador: Carta sobre la democracia, Ariel, Barcelona, 1998.

- Gouveia, Valdiney: La naturaleza de los valores descriptores del individualismo y del colectivismo: una comparación intra e intercultural, Tesis inédita de la Universidad Complutense de Madrid, Facultad de Psicología, Departamento de Psicología Social, Madrid, 2003.

- Habermas, Jürgen: Facticidad y validez. Sobre el derecho y el Estado democrático de derecho en términos de la teoría del discurso. Trotta, Madrid, 1998.

Problemas de legitimación en el capitalismo tardío. Traducción de José Luis Etcheverry, Ediciones Cátedra, Madrid, 1999.

- Hall, Jerome: Democracia e direito, Zahar, Rio de Janeiro, s/f.

- Held, David: Modelos de democracia, Alianza, Madrid, 1992.

Cosmopolitan Democracy: An Agenda for a New World Order, Cambridge, Polity Press, 1995.

- Hermet, GuY: En las fronteras de la democracia, Fondo de Cultura Económica, México, 1996.

- Hernández Sampieri, Roberto: Metodología de la investigación, McGraw-Hill, México, 1999 (2005).

- Hofstede, Geert: Culturas y organizaciones. El Software mental. La cooperación internacional y su importancia para la supervivencia. Versión de Escola Universitària de Turisme (ESMA), Alianza Editorial, Madrid, 1999.

- Huntington, Samuel: "El sobrio significado de la democracia", Revista Centro de Estudios Públicos, $\mathrm{n}^{\circ} 33,1989$.

El choque de civilizaciones, Paidós, Barcelona, 1997.

- Inglehart, Ronald: Modernización y posmodernización. El cambio cultural, económico y político en 43 sociedades. CIS-Siglo XXI Editores, Madrid, 1998.

- Jáuregui, Gurutz: La democracia en la encrucijada, Anagrama, Barcelona, 1995.

La democracia planetaria, Nobel, Oviedo, 2000.

- JaÑez Barrio, Tarcisio: El trabajo de investigación en Derecho, Universidad Católica Andrés Bello, Caracas, 1996.

- Kelsen, Hans: Esencia y valor de la democracia, Editora Nacional, México, 1974.

Escritos sobre la democracia y el socialismo, Debate, Madrid, 1988.

- Loughlin, John (compilador): La democracia regional y local en la Unión Europea, Comunidades Europeas, Bruselas, 1999. 
- Méndez, JuAn: "La cláusula democrática y el Derecho Interamericano", en Apuntes de Derecho sobre Democracia, una tarea pendiente, Facultad de Derecho, Universidad Diego Portales, Santiago, 2000.

- Michels, Robert: Los partidos políticos (2 vols.), Amorrortu, Buenos Aires, 1972.

- Nino, Carlos S.: La Constitución de la democracia deliberativa, Gedisa, Barcelona, 1997.

- Nussbaum, Martha: Las mujeres y el desarrollo bumano. El enfoque de las capacidades, versión castellana de Robert Vernet, Editorial Herder S.A. Barcelona, 2002.

- OBAndo, Iván: "La Constitución de 1980 y su democratización", en Revista de Derecho, Universidad Católica de Valparaíso, $\mathrm{N}^{\circ}$ XXII de 2001.

- O'Donnell, Guillermo: "Acerca del Estado en América Latina contemporánea: diez tesis para discusión”, en AA. Vv., La democracia en América Latina, Programa Naciones Unidas para el Desarrollo (PNUD), Buenos Aires, 2004.

- O'Donnell, G., y SCHMitTeR P.: Transitions from authoritain rule: tentative conclusions about uncertain democracies, Baltimore, Johns Hopkins University Press, 1986.

- Pennock, J. R.: Teoría política de la democracia, Princeton University Press, 1971.

- Peña, Carlos: "Democracia y minorías", en Apuntes de Derecho sobre Democracia, una tarea pendiente, Facultad de Derecho, Universidad Diego Portales, Santiago, 2000.

- Ponce de León Armenta, Luis: Metodología del Derecho, Porrúa, México, 1996.

- Prats, Joan: Gobernanza democrática, Barcelona, 2002.

- Rodríguez Palop, $\mathrm{M}^{\mathrm{a}}$ Eugenia: La nueva generación de derechos bumanos. Origen y justificación, Universidad Carlos III - Dykinson, Madrid, 2002.

- Rolla, Giancarlo: "Luces y sombras de la experiencia de las transiciones pactadas. Breve consideración sobre los límites de la Constitución vigente en Chile”, en Revista de Estudios Públicos (Nueva Época), n ${ }^{\circ}$ 115, Madrid, Enero-Marzo 2002.

- Ross, Alf: ¿Por qué la Democracia?, Centro de Estudios Constitucionales, Madrid, 1989.

- Rubio llorente, Francisco: La forma del poder, Centro de Estudios Constitucionales, Madrid, 1997.

- El constitucionalismo de los Estados integrados de Europa, Fundación Ortega y Gasset, Madrid, 1996.

- Sartori, Giovanni: “'Hasta dónde puede ir un gobierno democrático?", en Del Águila, R.; Vallestín, F. y otros: La democracia en sus textos. Alianza Editorial, Madrid, 1998. 
Homo Videns, la sociedad teledirigida, Taurus, Madrid, 1998.

La Sociedad Multiétnica. Pluralismo, multiculturalismo y extranjeros, Taurus, Madrid, 2001.

Teoría de la democracia (2 vol.), Alianza, Madrid, 1988.

Democracy, Enciclopedia internacional de Ciencias Sociales, vol. 4, Nueva York, 1968.

- Sen, Amartya: "Development as Capability Expansion", en Griffin, K. y Knight, J. (Eds.) Human development and the International Development Strategy for the 1990's, MacMillan-United Nations, Londres, 1990.

Development as Freedom, the First Presidential Lecture, Banco Mundial, 1997.

Nuevo examen de la desigualdad, versión de Ana María Bravo, Revisión de Pedro Schwartz, Alianza Editorial, Madrid, 1998.

Social Exclusion: Concept, Application, and Scrutiny. Social Development Papers $\mathrm{N}^{\circ} 1$, Office of Environment and Social Development, Asian Development Bank, June, 2000

- Schumpeter, Joseph: Capitalismo, sociedad y democracia, Aguilar, Madrid, 1968.

- Squella, Agustín y otros: Democratizar la democracia: Reformas pendientes, Lom, Santiago, 2000.

"Sobre la Democracia", en Apuntes de Derecho sobre Democracia, una tarea pendiente, Facultad de Derecho, Universidad Diego Portales, Santiago, 2000.

- Tomassini, Luciano: Gobernabilidad y políticas públicas en América Latina, Banco Interamericano de Desarrollo, Washington, 1996.

- Touraine, Alain: ¿Qué es la Democracia?, Fondo de Cultura Económica, México, 1998.

- Vallespin, Fernando: El futuro de la política, Taurus, Madrid, 2000 .

- Witker, Jorge: La investigación jurídica, McGraw-Hill, México, 1994.

- Zapata larraín, Patricio: La nueva Constitución y el fin de los enclaves autoritarios de 1980, en El Mercurio, Santiago, 18 de septiembre de 2005. 